\title{
A METÁFORA \\ NO LIVRO DIDÁTICO \\ DE ENSINO MÉDIO: \\ UM ESTUDO FEITO \\ A PARTIR DOS MANUAIS \\ APROVADOS \\ PELO PNLD 2014
}

\section{LA METÁFORA EN EL LIBRO DE TEXTO DE LA ENSEÑANZA SECUNDARIA: UN ESTUDIO HECHO DESDE LOS MANUALES APROBADOS POR PNLD 2014}

THE METAPHOR IN THE TEXTBOOK FOR SECONDARY EDUCATION: A STUDY OF THE HANDBOOKS APPROVED BY PNLD 2014

Antonio Cilírio da Silva Neto* Dieysa Kanyela Fossile** Kerlly Karine Pereira Herênio*** Universidade Federal do Tocantins

\footnotetext{
* Mestrando no Programa de Pós-Graduação em Letras: Ensino de Língua e Literatura, da Universidade Federal do Tocantins (UFT).E-mail: acilirio@bol.com.br

** Doutora em Linguística pela Universidade Federal de Santa Catarina (UFSC). Pesquisadora e professora adjunta II vinculada a o curso de Letras e a o Programa de Pós-Graduação em Letras: Ensino de Língua e Literatura, da Universidade FederaldoTocantins (UFT). E-mail: dieysa@mail.uft.edu.br. 
RESUMO: Neste artigo, analisamos como a metáfora vem sendo discutida e abordada nos Livros Didáticos atuais de Língua Portuguesa. A princípio, três manuais didáticos de coleções distintas são analisados. Como aporte teórico para o desenvolvimento deste estudo, utilizamos pesquisas de Silva (1997), Batista (2003, 2004), Bunzen (2005, 2007, 2014), tal como, o guia de Livros Didáticos - PNLD (2014), os quais apresentam discussões sobre os manuais escolares. Para os estudos centrados na metáfora, utilizamos pesquisas de Black (1962, 1966, 1992, 1993), Lakoff e Johnson (2002 [1980]), Sardinha (2007) e Fossile (2011, 2013a, 2014). Ressaltamos que os resultados apresentados não são conclusivos ou exaustivos, porém, a partir do estudo realizado, verificamos que os resultados alcançados ratificam que o conceito tradicional de metáfora, como um recurso essencialmente ornamental, retórico e relacionado à linguagem figurada e ao campo literário, ainda é propagado nos Livros Didáticos atuais de Língua Portuguesa.

PALAVRAS-CHAVE: livros didáticos atuais; Língua Portuguesa; metáfora; ensino.

RESUMEN: En este artículo intentamos analizar cómo la metáfora viene siendo discutida y tratada en los libros de texto actuales de la lengua portuguesa. En principio, tres manuales didácticos de colecciones diferentes están siendo analizados. Como contribución teórica para el desarrollo de este estudio, usamos investigaciones de Silva (1997), Batista (2003, 2004), Bunzen (2005, 2007, 2014), así como, la guía propia de libros de texto - PNLD (2014) que presentan discusiones sobre los manuales escolares. Para los estudios centrados en la metáfora, usamos investigaciones de Black (1962, 1966, 1992, 1993), Lakoff y Johnson (2002 [1980]), Sardinha (2007) y Fossile (2011,2013a, 2014). Enfatizamos que los resultados aquí presentados no son concluyentes o agotados, sin embargo, desde el estudio realizado, verificamos que los resultados alcanzados ratifican que el concepto tradicional de metáfora, como un recurso esencialmente ornamental, retórico y relacionado con la lengua figurada y el campo literario, todavía es difundido en los libros de texto actuales de lengua portuguesa.

PALABRAS CLAVE: libros de texto actuales; Lengua Portuguesa; metáfora; enseñanza.

ABSTRACT: This article aims to analyze how the metaphor has been discussed and addressed in current textbooks in Portuguese. At first, three textbooks of different compilations were analyzed. As a theoretical contribution for the development of this study we have used the researches of Silva (1997), Baptist (2003, 2004), and Bunzen (2005, 2007, 2014), as well as the -PNLD's handbooks themselves (2014), which present several discussions on textbooks. For the studies focused on metaphor, we have researched Black (1962, 1966, 1992, 1993), Lakoff and Johnson (2002 [1980]), Sardinha (2007), and Fossile (2011a, 2011b, 2013a, 2014). We would like to emphasize that the results presented hereby are not exhaustive or conclusive. However, with this study we have found the results obtained confirm that the traditional metaphor concept as a feature which is essentially ornamental, rhetorical, and related to figurative language and to the literary field, is still disseminated in current Portuguese language textbooks.

KEYWORDS: portuguese textbooks; metaphor; education.

\section{CONSIDERAÇÕES INICIAIS}

Neste artigo, propomos discutir e analisar como a metáfora vem sendo abordada e conceituada nos livros didáticos atuais de Língua Portuguesa. Com base na pesquisa realizada, verificamos que grande parte dos manuais escolares destinados às primeiras séries do Ensino Médio da Educação Básica faz referência às figuras de linguagem. Dentre essas figuras apresentadas nos compêndios escolares, está a metáfora. A princípio, a partir do estudo realizado, parece-nos que a metáfora ainda é compreendida e disseminada nos manuais escolares como uma simples figura retórica, que desempenha uma única função, ornamentar/embelezar a linguagem.

Para tanto, neste artigo, primeiramente, observamos como são organizados e avaliados os livros didáticos de Língua Portuguesa; em seguida, pesquisamos o que é metáfora e um pouco sobre a sua trajetória; e, na sequência, analisamos como a metáfora é tratada nos manuais: (i) Viva Português (2013) das autoras Elizabeth Campos, Paula Marques Cardoso e Sílvia Letícia de Andrade; (ii) Língua Portuguesa (2013) das autoras Roberta Hernandes e Vima Lia Martin e (iii) Vozes do Mundo: Literatura, Língua e Produção de Texto (2013) de Lília Santos Abreu-Tardelli, Lucas Sanches Oda, Maria Tereza Arruda Campos e Salete Toledo. 


\section{LIVROS DIDÁTICOS DE LÍNGUA PORTUGUESA (LDPS) E CRITÉRIOS DE AVALIAÇÃO}

Conforme Bunzen (2014), estudos revelam que os materiais didáticos, em especial, o livro didático impresso, tem se tornado o principal objeto de investigação de variadas áreas de conhecimento. Pesquisadores objetivam compreender as diversas facetas que este material didático pode apresentar, isto é, analisam (i) as características físicas, assim como (ii) as características discursivas e as finalidades sociais desses manuais de ensino, tal como (iii) a maneira como esses materiais apresentam, transmitem e discutem conhecimentos científicos e (iv) a forma como propiciam esse conhecimento científico para os alunos, para os leitores e/ou usuários. Com base em Choppin (2004), Bunzen (2014) afirma que, nos últimos trinta anos, houve uma propagação de estudos sobre materiais didáticos, peculiarmente, sobre o livro escolar.

Com base nos estudos de Silva (1997), Batista (2003) e Bunzen (2005; 2007; 2014), verificamos que, desde a década de 1980 , pesquisas sobre o Livro Didático de Língua Portuguesa, (doravante LDP), firmaram-se, principalmente, em Programas de PósGraduação em Letras ou Linguística. Conforme Bunzen (2014, p. 270), essas pesquisas tinham e têm como objetivo principal investigar os conteúdos e as metodologias adotadas para ensiná-los, analisando especialmente a concepção de língua(gem) implicitamente inserida nesses manuais ou materiais analisados. Então, segundo o autor, diante dessas pesquisas, os Livros Didáticos que foram confeccionados nos anos 1980 e 1990, pelo fato de apresentarem problemas de caráter teórico e metodológico, sofreram duras críticas. De certa forma, os LDPs ainda continuam sendo o ponto central de estudos e de críticas referentes (i) ao conceito de língua(gem), (ii) às ilustrações e às imagens, (iii) aos exercícios e às atividades de gramática, (iv) às atividades de interpretação textual, entre outras questões. É importante ressaltar que em uma época em que os LDPs

[...] não eram oficialmente avaliados no âmbito do Programa Nacional do Livro Didático (PNLD), mas eram distribuídos para as escolas públicas (especialmente as de $1^{\circ}$ grau menor), as pesquisas em Letras/Linguística funcionavam como um termômetro da qualidade da produção didática nacional. (BUNZEN, 2014, p. 271)

Nos anos 1970 e 1980, procuravam-se os culpados pela crise e pelo insucesso do ensino de língua materna na escola. A princípio, os linguistas foram apontados como os culpados pela crise que se proliferava no ensino; porém, nas décadas de 1980 e 1990, os Livros Didáticos passaram a ser os principais responsáveis pelo insucesso escolar, no que diz respeito ao processo de leitura e de escrita. Nessa época, pesquisas mostravam que esses materiais escolares eram a única ferramenta de trabalho adotada pelo professor. Então, o LDP foi de fato compreendido como o grande vilão, pois apresentava conteúdos e metodologias de ensino, compreendidos como tradicionais pela ciência moderna, e quase não abriam espaço enunciativo para divulgar as ideias dos vários campos da Linguística. (BUNZEN, 2014, p. 271-272)

Somente os conteúdos que eram apresentados no manual didático eram ensinados nas aulas, e, muitas vezes, esse compêndio não estava voltado e nem levava em conta o contexto do aluno. Assim, o LDP passou a ocupar papel de destaque nas aulas de português e o professor passou a tornar-se dependente deste artifício de ensino. Conforme apontam estudos divulgados em 27 de fevereiro de 2013 pela Agência Brasil, no site Último Segundo e conforme ressaltado por Fossile (2013b, p. 403), no Brasil, ainda hoje, $98 \%{ }^{1}$ dos professores de escolas públicas adotam o Livro Didático como ferramenta de trabalho.

Diante desta situação, conforme Bezerra (2007), a partir da última década do século XX, o Estado passou a intervir neste assunto que diz respeito à produção e à organização dos Livros Didáticos, por meio de programas de avaliação do MEC. A partir daí, os Livros Didáticos foram forçados a investir em mudanças nos conteúdos, nas metodologias e nos conceitos teóricos. Desta forma, em 1997 foi organizada uma comissão para definir critérios de avaliação do Livro Didático, isto é, nesse ano, surgiu o Plano Nacional do Livro Didático (doravante PNLD). O “[...] PNLD [...], a partir da Avaliação, estabeleceu perspectivas teóricas e metodológicas bastante definidas para o LDP” (RANGEL, 2005, p. 14 apud MORAIS, 2013, p. 31). Morais (2013, p. 31), com base em Rangel (2005), argumenta que critérios estabelecidos pelo PNLD contribuíram para analisar se o manual:

${ }^{1}$ Estudo desenvolvido pelo QEdu: Aprendizado em Foco (uma parceria entre a Meritt e a Fundação Lemann), organização sem fins lucrativos voltada para a Educação. 
(a) oferece ao aluno textos diversos e heterogêneos, do ponto de vista do gênero e do tipo de texto; (b) prevê atividades de leitura capazes de desenvolver no aprendiz as competências leitoras implicadas do grau de proficiência que se pretende levá-lo a atingir; (c) ensina a produzir textos, por meio de propostas que contemplem tanto os aspectos envolvidos nas condições de produção, quanto os procedimentos e estruturas próprias de textualização; mobiliza corretamente a língua oral, quer para o desenvolvimento da capacidade de falar/ouvir, quer para a exploração das muitas interfaces entre oralidade e escrita; (e) desenvolve os conhecimentos linguísticos de forma articulada com as demais atividades.

Neste estudo que estamos desenvolvendo, interessam-nos os LDPs de Ensino Médio. De acordo com o Guia de Livros Didáticos do Ensino Médio - PNLD (2014, p. 6), somente em 2004, iniciaram-se as avaliações dos manuais didáticos de português, por meio do então conhecido Programa Nacional do Livro para o Ensino Médio (PNLEM). Nesta época, foram avaliados somente livros de Matemática e de Língua Portuguesa destinados a alunos da primeira série do Ensino Médio. Esses manuais foram distribuídos para as regiões Norte e Nordeste, em 2005. Somente em 2006, o MEC ampliou a distribuição dos Livros Didáticos de Matemática e Língua Portuguesa para as regiões Sul, Sudeste e Centro-Oeste. Em 2008, ainda por meio do PNLEM, deu-se a universalização da distribuição do Livro Didático de Português, Matemática, Física, Química, História, Geografia e Biologia.

Em 2012, o antigo PNLEM foi incorporado ao Programa Nacional do Livro Didático (PNLD), executado pelo FNDE2 e pela Secretaria da Educação Básica (SEB/MEC). [...] no PNLD 2015 serão distribuídos além de livros didáticos de Língua Portuguesa, Língua Estrangeira Moderna (Inglês e Espanhol), Matemática, História, Geografia, Sociologia, Filosofia, Biologia, Física e Química, os livros de Arte. Trata-se da primeira vez que Arte participa do PNLD, sendo este um ganho significativo para as escolas do ensino médio. (PNLD, 2015, p. 6).

As coleções de Livros Didáticos do Ensino Médio, em 2015, são de dois tipos de composição, o Tipo 1 diz respeito à obra multimídia composta de livros digitais e livros impressos, já o Tipo 2 corresponde à obra impressa composta de livros impressos e PDF. Deste modo, os professores poderão selecionar tanto livros do Tipo 1 quanto livros do Tipo 2.

"Diante dessa política de avaliação [...], os autores dos livros didáticos passam a se preocupar mais com que conteúdo abordar, de que maneira e se determinado LD se adequará ao contexto dos discentes [...]" (MORAIS, 2013, p. 31). Desta forma, conforme apresentamos no início desta seção, com base nos estudos de Bunzen (2014), verificamos que muitas pesquisas analisam e investigam os conteúdos que são abordados nos LDPs, tal como as metodologias que são utilizadas para ensinar esses conteúdos, porém, a partir dessa questão, surge-nos uma objeção, isto é, realmente, os conteúdos abordados nos LDPs contemporâneos, que passaram/passam por avaliações, são esclarecedores e apresentados de forma atualizada, levando em consideração os estudos linguísticos modernos? Por exemplo, os conceitos e as explicações concernentes a determinados assuntos que compõem o LDP atual contemplam os estudos voltados à linguística ou somente à gramática normativa tradicional?

Atualmente, Fossile (2013b), por meio de projeto de pesquisa ${ }^{3}$, analisa como a semântica vem sendo tratada nos LDPs da Educação Básica. A pesquisadora tem verificado que nos manuais escolares que analisou ainda há uma elevada preocupação com a transmissão de nomenclaturas e de conteúdos de caráter um tanto gramatical. Assim, os estudos iniciais demonstram, a princípio, que os manuais didáticos ainda são elaborados sob o enfoque tradicional. Por exemplo, a maioria dos LDPs (se não todos!) destinados às primeiras séries do Ensino Médio da Educação Básica fazem referência às figuras de linguagem. Dentre essas figuras, destaca-se a metáfora; logo, verificamos que "nos livros didáticos [...] é comum identificarmos a metáfora como nada mais que uma figura de estilo ou figura de linguagem” (FOSSILE, 2014, p. 159). Desta forma, “[...] é geralmente estudada em literatura como uma técnica de poetas para expressar sentimentos e também como um traço particular que ajuda a definir o estilo de um escritor; até por isso, às vezes as figuras são chamadas de estilo” (SARDINHA, 2007, p. 22-23).

\footnotetext{
${ }^{2}$ Fundo Nacional de Desenvolvimento da Educação.

${ }^{3}$ Livros didáticos de Língua Portuguesa: com o olhar focado no ensino de semântica.
} 
Diante disso, é possível compreender que a metáfora é entendida como uma simples figura retórica que desempenha uma única função, ornamentar/embelezar a linguagem, sendo importante apenas para o campo literário. Sardinha (2007, p. 22) é categórico ao afirmar que "nas gramáticas, dicionários e enciclopédias, [...] [as figuras de linguagem] tendem a ser ilustradas com exemplos de textos de poetas e escritores consagrados. Isso é consistente com a visão de que essas figuras são recursos de estilo, de ornamento, que servem a tipos de expressão culturalmente prestigiados”. Tal fato nos leva a conjeturar que os conceitos de metáfora, que são apresentados nos LDPs, não contemplam as teorias e os estudos que surgiram sobre essa figura de estilo, por isso a metáfora acaba sendo (re)conhecida pela maioria dos alunos e professores como um simples recurso ornamental da linguagem e é muitas vezes estudada apenas nas aulas de literatura.

Diante desta questão, pretendemos neste estudo, analisar e descrever como a metáfora é conceituada nos LDPs atuais, já que esses manuais passam por cuidadoso processo de avaliação. Para isso, é necessário, antes de tudo, entendermos o que é metáfora, e na sequência, analisarmos como, de fato, esse recurso da linguagem é tratado nos LDPs mais recentes.

\section{METÁFORA: ALÉM DO VALOR ORNAMENTAL}

Deparamo-nos com algumas inquietações, ao observarmos como a metáfora vem sendo apresentada e discutida nos LDPs atuais. A partir daí, debruçamo-nos sobre os seguintes questionamentos: (i) Afinal, o que é metáfora? (ii) Como conceituá-la? (iii) Qual é o conceito de metáfora que veicula nos LDPs atuais? Nesta seção, nesse sentido, tentamos buscar respostas para as questões colocadas. Inicialmente, realizamos um levantamento teórico sobre a metáfora e verificamos que "a noção mais antiga de metáfora no Ocidente vem de Aristóteles, do século IV a. C. Segundo ele, uma metáfora é o uso do nome de uma coisa para designar outra” (SARDINHA, 2007, p. 20). Desta maneira, para Aristóteles, a metáfora “[...] consiste no transportar para uma coisa o nome de outra, ou do gênero para a espécie, ou da espécie para o gênero, ou da espécie de uma para a espécie de outra, ou por analogia” (ARISTÓTELES, 1996, cap. XXI, 1457b-6, p. 92). Giambatista Vico (1668 - 1744) foi um dos primeiros pesquisadores que apresentou questionamentos acerca da teoria de Aristóteles ${ }^{4}$ (SÁBATO, 1982, p. 117). Em relação à teoria aristotélica da metáfora, Zanotto (1998, p. 14) afirmou que durante vários séculos vigorou "a teoria aristotélica da metáfora como figura de retórica, com a única função de ornamentar [...], como um dogma inquestionável [...]”.

A partir de 1970, muitos questionamentos começaram a surgir sobre o caráter retórico da metáfora, "[...] sobretudo no que diz respeito aos pressupostos da ausência de valor cognitivo e da determinação do significado" (ZANOTTO, 1998, p. 14). Por exemplo, os estudos de Lakoff e Johnson (2002 [1980]) muito se destacaram na década de 1980 trazendo um novo olhar para esse fenômeno da linguagem. Segundo Zanotto (1998, p. 14-15),

para Lakoff e Johnson [...], a visão errônea da metáfora como simples ornamento sem função informativa justifica-se pelo que eles denominam mito do objetivismo, que dominou a cultura ocidental, em particular, a filosofia ocidental, dos pré-socráticos até os dias de hoje. Para esses autores, o objetivismo é um termo genérico, que engloba o Racionalismo Cartesiano, o Empirismo, a Filosofia Kantiana, o Positivismo Lógico, etc. Em suma ele abrange todas as correntes da filosofia ocidental em que houve a hegemonia da razão e um medo do sentimento e da imaginação. Nesse contexto, a metáfora e outras espécies de linguagem figurada deveriam ser sempre evitadas quando se pretendesse falar objetivamente.

Então, verificamos que, nas últimas décadas, houve uma verdadeira virada em relação ao entendimento deste recurso da linguagem, o qual está sendo reconhecido e compreendido como um fundamental instrumento de cognição, que realiza funções importantes nos nossos processos cognitivos e perceptuais. "Esse foi o grande insight de Reddy (1979) e Lakoff e Johnson (2002 [1980]), que descobriram o caráter cognitivo metafórico que permeia a linguagem ordinária ou cotidiana” (ZANOTTO, 1998, p. 15).

${ }^{4}$ Conferir também Fossile (2011b, 2014). 
Para a visão tradicional, a linguagem figurada só é encontrada em textos literários. É importante ressaltarmos que a concepção de metáfora na perspectiva lakoffiana ignora a concepção tradicional, a qual é defendida pela versão aristotélica, de que a metáfora é um fenômeno que desempenha a função de ornamento. No livro Metáforas da Vida Cotidiana de Lakoff \& Johnson (2002 [1980], p. 45), os autores afirmam que

[...] a metáfora é, para a maioria das pessoas, um recurso da imaginação poética e um ornamento retórico [...]. Mais do que isso, a metáfora é usualmente vista como uma característica restrita à linguagem, uma questão mais de palavras do que de pensamento ou ação. Por essa razão, a maioria das pessoas acha que pode viver perfeitamente bem sem a metáfora. Nós descobrimos, ao contrário, que a metáfora está infiltrada na vida cotidiana, não somente na linguagem, mas também no pensamento e na ação. Nosso sistema conceptual ordinário, em termos do qual não só pensamos, mas também agimos, é fundamentalmente metafórico por natureza.

Desta forma, verificamos que Lakoff e Johnson (2002 [1980]) defendem que a metáfora é um fenômeno que faz parte da experiência humana, da experiência diária do uso da língua e também da ação humana. Para esses estudiosos a metáfora não é somente um recurso literário, mas é um recurso que exerce uma função primordial no nosso sistema conceitual e na linguagem diária. Esses pesquisadores sustentam que o nosso pensamento é metafórico pelo fato de atuar nos conceitos, que são representados através da língua. Diante desta colocação, percebemos que é necessário explicar o que é uma expressão metafórica e o que é uma metáfora conceptual. Assim sendo, esclarecemos que a expressão metafórica é a expressão linguística que representa uma metáfora conceptual, já a metáfora conceptual é o próprio pensamento metafórico (LAKOFF; JOHNSON, 2002 [1980]). Desta maneira, as expressões linguísticas são utilizadas para externar os conceitos metafóricos que temos no pensamento.

A Teoria da Metáfora Conceptual de Lakoff e Johnson (2002 [1980]) propõe que a metáfora é um mecanismo formado por imagens mentais, que instauram projeções entre domínios distintos e que se realizam de diversas maneiras no nível linguístico. Como exemplo, citamos:

[...] O AMOR É UMA VIAGEM5 [...] é um exemplo de metáfora conceptual (e não de expressão metafórica), que faz uma projecção entre um Domínio de Origem (VIAGEM) e um Domínio Alvo (AMOR), e que pode ter diversas realizações lingüísticas, tais como "Estamos numa encruzilhada", "Olha onde chegou a nossa relação" ou "Estamos a ir muito depressa". São, portanto, diferentes expressões lingüísticas que veiculam uma única metáfora conceptual. A metáfora O AMOR É UMA VIAGEM não se caracteriza por uma palavra ou expressão particular, mas antes por uma projecção ontológica onde se cruzam domínios conceptuais. Neste caso, pretende explicar-se a noção abstrata AMOR, estabelecendo correspondências com a nossa experiência concreta de uma VIAGEM. Far-se-á, então, uma projecção metafórica entre ambos os domínios, colocando em destaque o fato de, por exemplo, os amantes corresponderem a viajantes, os seus objectivos serem o destino de uma viagem ou de os obstáculos consistirem em encruzilhadas (FERRÃO, [s. d.], p. 6 apud FOSSILE, 2011b, p. 41).

Portanto, a Teoria da Metáfora Conceptual sustenta que a metáfora é um fenômeno exclusivo do pensamento e só secundariamente um evento da linguagem (COIMBRA, 1999, p. 44). Além da perspectiva lakoffiana, há outras teorias da metáfora, tal como a de Max Black (1962; 1966; 1992; 1993), conhecida como Teoria da Interação Semântica. A proposta de Black defende que a metáfora é um fenômeno muito peculiar em que os termos que formam um enunciado metafórico interagem, simultaneamente, criando uma operação mental, na perspectiva de que a linguagem elabora maneiras de pensar. Essa perspectiva teórica sustenta que tanto fatores cognitivos quanto fatores linguísticos dizem respeito a este fenômeno denominado metáfora. Então, observamos que a versão interacionista sustenta que a metáfora passa a ser entendida como um recurso que concebe conhecimento. Conforme Moura e Pereira (2008, p. 02),

[...] a linha interacionista [...] não vê a metáfora como uma mudança de significado apenas, isto é, uma superposição de uma acepção nova à acepção antiga da palavra, mas afirma que há uma interação entre o tópico

\footnotetext{
${ }^{5}$ Metáforas conceptuais como "O AMOR É UMA VIAGEM" são grafadas com letras maiúsculas; enquanto expressões metafóricas como (a) "Estamos numa encruzilhada", (b) "Olha onde chegou a nossa relação" são escritas com letras minúsculas. Muitos autores seguem essa concepção introduzida por Lakoff e Johnson (2002 [1980]).
} 
e o veículo do enunciado metafórico, por isso, não há uma substituição de significados, porém um ponto de interseç̧ão entre os significados [...].

A partir da explanação feita e pensando nos questionamentos (i) e (ii), apresentados no início desta seção, é possível concluir que a metáfora não pode ser reduzida a uma simples figura de linguagem, uma vez que ela não executa somente a função de ornar e/ou de substituir termos que a compõe, tornando a linguagem, simplesmente, mais bela. Esse recurso linguístico é muito mais que isso, está impregnado no pensamento e por isso na vida cotidiana; além disso, é um fenômeno apto a gerar conhecimento. A partir do estudo realizado, verificamos, conforme apontado por Zanotto $(1998$; 1995), que a metáfora ainda é compreendida como uma simples figura de retórica, que tem tão somente a função de embelezar a linguagem, e é essa a concepção que a maioria das pessoas também ainda tem quando ouvem ou se referem à metáfora ${ }^{6}$. A princípio, parece-nos que essa concepção continua sendo divulgada até mesmo nos atuais LDPs. Uma análise mais apurada sobre isso e a tentativa de alcançar uma resposta plausível e viável para o questionamento $\left(\right.$ (iii $^{7}$, apresentado na introdução desta seção, perpassarão a próxima parte deste texto.

\section{ANALISANDO COMO A METÁFORA É CONCEITUADA E DISCUTIDA NOS LIVROS DIDÁTICOS ATUAIS DE LÍNGUA PORTUGUESA}

O objetivo principal deste estudo é verificar como a metáfora é explicitada nos LDPs atuais, isto é, pretendemos analisar se a metáfora ainda continua sendo conceituada como um mero recurso ornamental da linguagem, ou se houve, de certa forma, algum progresso na forma como ela é abordada e discutida nos manuais escolares. Salientamos que a escolha dos LDPs, para o desenvolvimento deste estudo, não se deu de maneira aleatória. Selecionamos, preferencialmente, compêndios recentes, que foram avaliados no âmbito do PNLD, garantindo o ciclo trienal de 2015.

Verificamos que a metáfora só é, efetivamente, apresentada e abordada nos manuais didáticos destinados à primeira série do Ensino Médio, deste modo, optamos por analisar apenas esses livros, já que nosso foco de investigação, ali reside. O primeiro LDP selecionado para este estudo é o manual Viva Português, da editora Ática, de 2013, das autoras Elizabeth Campos, Paula Marques Cardoso e Sílvia Letícia de Andrade. Neste manual, localizamos a seguinte explicação para a metáfora:

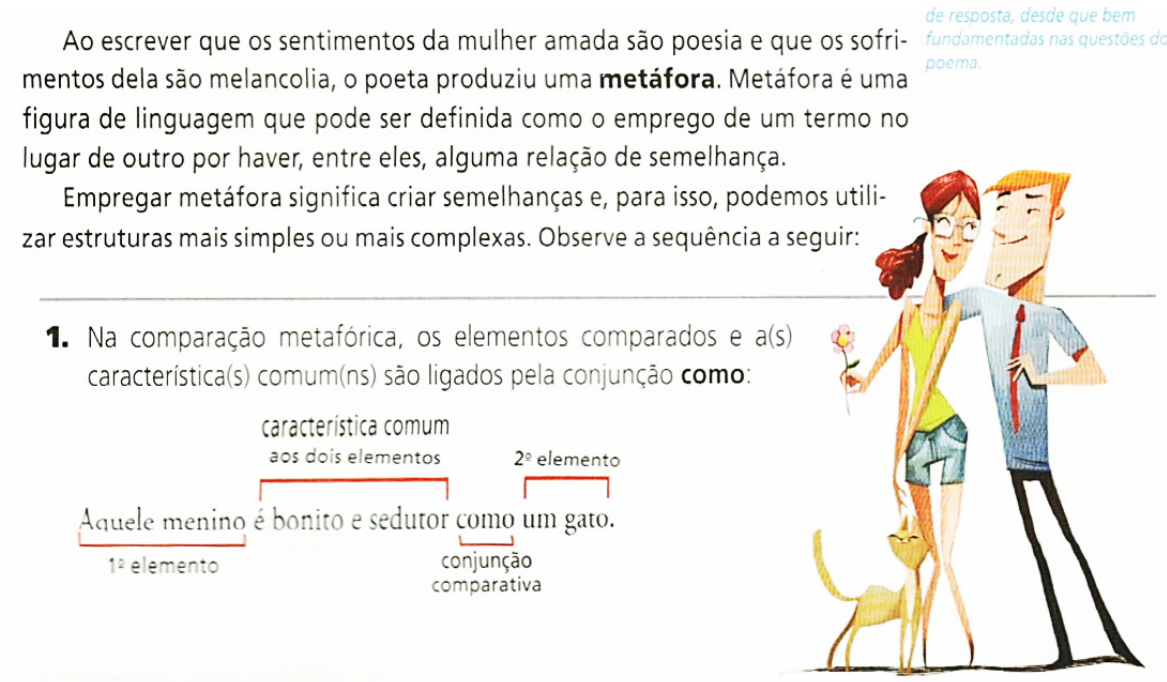

Quadro 01: Explicação concernente à metáfora

Fonte: Campos, Cardoso e Andrade (2013, p.233)

\footnotetext{
${ }^{6}$ Sobre esse assunto consultar também Fossile (2011, 2014).

${ }^{7}$ Qual é o conceito de metáfora veiculado nos LDPs atuais?
} 
O conceito apresentado à metáfora neste LDP gera discussão. Primeiramente, fica visível que a metáfora ainda é entendida como uma figura de linguagem, que desempenha a função de substituir e/ou comparar termos. O exemplo apresentado faz alusão à comparação metafórica e não à metáfora em si, isso acaba gerando certa confusão entre metáfora e comparação metafórica, desta maneira, questionamos: (i) metáfora e comparação metafórica são recursos iguais? (ii) Ou seriam recursos distintos? Conforme podemos verificar no quadro 01 , a explicação e a exemplificação concernentes à comparação metafórica transmitem que a conjunção "como" desempenha uma função especial, ligando elementos que são comparados e as características comuns. Parecenos que as autoras tratam comparação e metáfora como sendo o mesmo fenômeno linguístico. Na página seguinte, 234, as autoras continuam exemplificando a metáfora, mas a conceituação ainda não é totalmente esclarecedora. Observemos:

2. Metáfora em que aparecem os dois elementos comparados, mas sem o atributo que é comum a eles e sem a conjunção como:

Aqucle menino é um gato.

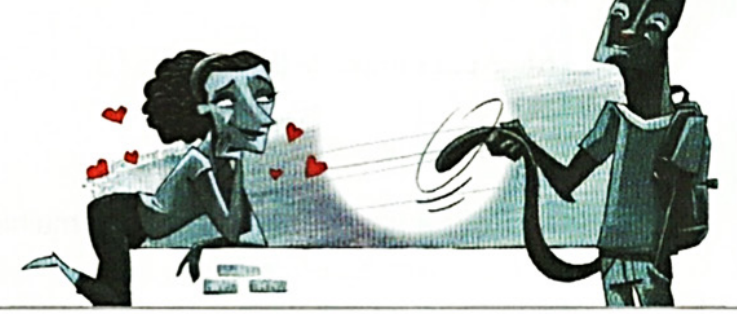

3. Metáfora em que não aparece nem o segundo elemento da comparação nem o atributo comum aos dois elementos:

- Oi, gato, tudo bem?

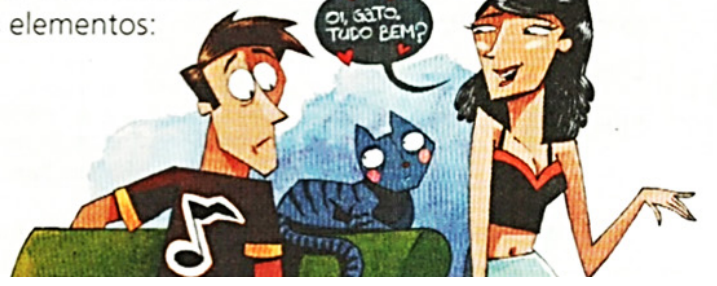

Quadro 02: Explicação concernente à metáfora

Fonte: Campos, Cardoso e Andrade (2013, p.234)

A partir do exposto, percebemos que essa abordagem sobre a metáfora, transmitida neste manual escolar, ainda está presa à concepção aristotélica da metáfora. Por exemplo, Ricoeur (2005) expõe que Aristóteles não tinha como propósito explicar a metáfora pela comparação; mas, sim, o contrário, objetivou explicar a comparação pela metáfora. Além disso, o autor esclarece que, para Aristóteles, o fato do termo de comparação não se fazer presente na metáfora não quer dizer que a metáfora seja uma comparação abreviada, mas se dirá o contrário, que a comparação é uma metáfora desenvolvida. Ainda com relação a essa questão, nos estudos de Ricoeur (2005), verificamos que o autor afirma que toda metáfora acaba sendo uma comparação implícita, enquanto que a comparação é uma metáfora desenvolvida. Com base nos estudos de Ricoeur, julgamos importante esclarecer que ao realizar estudos referentes à aproximação da metáfora com a comparação, Aristóteles percebeu certa superioridade da metáfora sobre a comparação, pelo fato da metáfora ser entendida e julgada como sendo mais agradável, mais elegante e predicativa ${ }^{8}$ ao ser equiparada à comparação. Então Ricoeur (2005), a partir dessa aproximação entre metáfora e comparação, defendida por Aristóteles; sustenta que a linguagem que é feita de metáforas resulta em um enigma. A essência desse enigma permite falar de coisas reais aproximando termos inconciliáveis, o autor enfatiza que tal coisa seria possível apenas com a metáfora (FOSSILE, 2011). Diante desta exposição, percebemos que Aristóteles sustentou que há uma aproximação entre metáfora e comparação, mas não

${ }^{8}$ Com base nos estudos de Ricoeur (2005) e de Cohen (1974), compreendemos que para que a predicação seja dita metafórica, é necessário que os dois termos que constituem a metáfora pertençam a campos semânticos distintos. Por exemplo, na sentença “Teu amor é um microondas", há uma relação predicativa de dois termos que pertencem a campos semânticos distintos: "amor" (sentimento) e "microondas" (eletrodoméstico). 
defendeu que são fenômenos idênticos ou iguais; já a explicação concernente à metáfora, abordada no LDP, Viva Português, não esclarece se metáfora e comparação metafórica são recursos linguísticos distintos, ou semelhantes, ou iguais.

Porém, consideramos importante ressaltarmos que esta explicação à metáfora também apresenta um ponto interessante, e, talvez, positivo, quando as autoras afirmam que empregar metáfora significa criar semelhanças. Essa asserção induz que a metáfora desempenha uma função que vai além da decorativa, podendo criar semelhanças ou significados. Parece-nos, a princípio, que essa afirmação tem alguma relação com a Teoria Interacionista de Max Black (1993), que sustenta que uma metáfora não só identifica as semelhanças que podem ser localizadas em sentenças desse tipo, mas também as cria, sendo capaz de gerar uma operação mental. No entanto, verificamos que o fator cognitivo da metáfora não é valorizado e nem enfatizado nas explicações e abordagens apresentadas, dando a impressão que a metáfora continua sendo uma mera figura retórica.

Na sequência, analisamos o LDP da editora Positivo, de 2013, das autoras Roberta Hernandes e Vima Lia Martin. Nesse, a metáfora continua sendo transmitida como uma figura de linguagem. Verifiquemos o quadro abaixo:

\section{Figuras de linguagem}

Leia esta tira e identifique a figura de linguagem nele empregada.

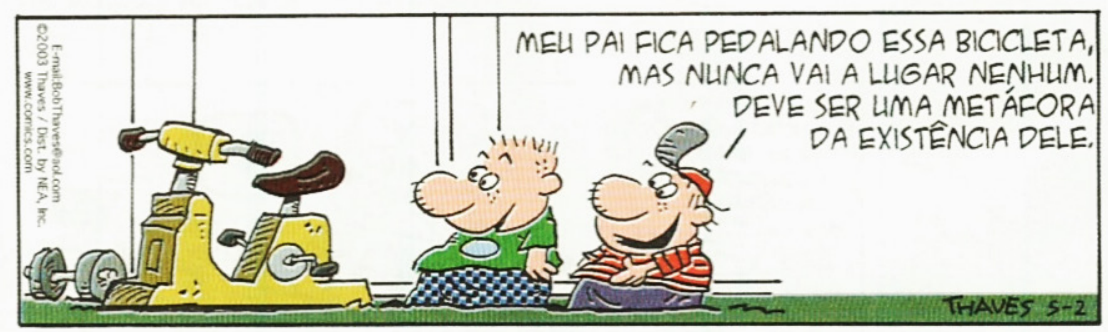

Note que, nessa tira, a figura de linguagem usada foi a metáfora: ocorreu uma comparação implícita entre a ação de andar de bicicleta e a vida do pai do personagem, que estaria parada, sem objetivo.

Em toda língua há uma série de recursos expressivos que auxiliam na comunicação e ampliam os sentidos corriqueiros das palavras e das expressões por meio da linguagem figurada. Entre os recursos empregados para expandir os sentidos de um texto estão as figuras de linguagem, frequentemente usadas em poemas, anúncios publicitários, em alguns gêneros jornalísticos, como o ensaio e a crônica, em ditados populares, em canções e mesmo em conversas cotidianas.

As figuras de linguagem são construidas com o uso do sentido figurado ou conotativo de uma palavra ou expressão. Ao se valer de uma figura de linguagem, o usuário da língua potencializa os sentidos do texto que produz, além de possibilitar mais de uma leitura para ele, já que cabe ao interlocutor identificar os sentidos sugeridos com base no contexto de produção do texto.

Quadro 03: Explicação concernente à metáfora

Fonte: Hernandes e Martin (2013, p.238)

Neste manual, a metáfora continua sendo tratada como uma comparação. A abordagem segue ancorada ao paradigma tradicional de linguagem figurada e ornamentada. Porém, é importante perceber que essa explicação, a princípio, tenta mostrar que esse recurso da linguagem não é só usado em poemas (ou na literatura), mas também em gêneros jornalísticos e mesmo em conversas cotidianas. Desta forma, concluímos que a explicação dá ênfase à ampliação do uso da metáfora. As autoras prosseguem com a explicação sobre o assunto na página seguinte, 239. 


\section{Metáfora}

Consiste, em linhas gerais, numa comparação abreviada, implicita, sem o uso de expressões comparativas. Na metáfora, a relação se dá por meio de uma semelhança, normalmente implícita, entre possiveis sentidos de cada uma das palavras ou expressões. Consiste, portanto, em atribuir a uma palavra ou expressão um sentido que não lhe é próprio, mas de outra palavra ou expressão com a qual estabelece alguma relação de semelhança. É uma das figuras de linguagem mais comuns, que está na raiz do texto literário, por princípio, metafórico. Observe.
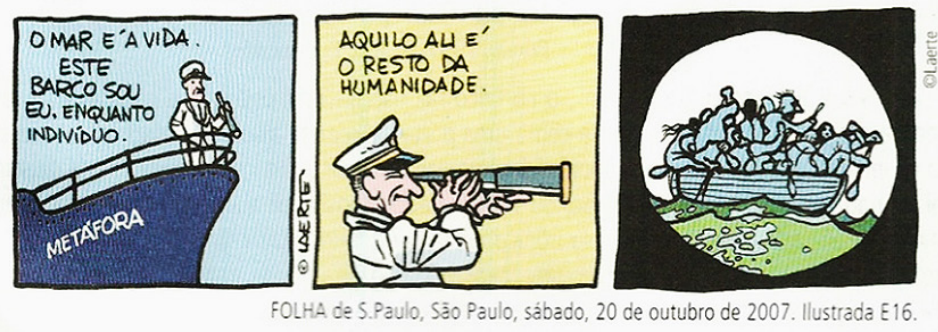

Quadro 04: Explicação concernente à metáfora

Fonte: Hernandes e Martin (2013, p.239)

Na segunda parte da abordagem, as autoras esclarecem que a metáfora não é uma simples comparação, mas sim uma comparação abreviada. Desta maneira, compreendemos que ao afirmarem que a metáfora é uma comparação abreviada tentam, simplesmente, mostrar que há ausência de expressões comparativas ${ }^{9}$ na formação estrutural da sentença metafórica. Diante disso, é importante retomarmos que para Aristóteles o fato do termo de comparação não estar presente na metáfora não significa que a metáfora é uma comparação abreviada, já para Ricoeur (2005), nesse caso, toda metáfora acaba sendo uma comparação implícita.

Esta explicação também apresenta lacunas ao abordar que na metáfora, a relação se dá por meio de uma semelhança, normalmente implícita, entre possíveis sentidos de cada uma das palavras ou expressões. Afinal, como se daria essa relação de semelhança implícita entre possíveis sentidos de cada uma das palavras ou expressões? Ora, tal como já abordado, a metáfora, conforme a Teoria Interacionista de Max Black (1993), não apenas aponta e reconhece as semelhanças que podem ser identificadas em sentenças metafóricas, mas também as produz. Isto é, a metáfora é capaz de criar, conceber e até mesmo de "parir" ${ }^{10}$, a partir da interação entre os elementos que compõem a sentença metafórica, uma operação mental, sob a concepção de que a linguagem cria realidades e maneiras de pensar.

Por exemplo:

Teu namorado (TÓPICO ${ }^{11}$ ) é um chiclete (VEÍCULO ${ }^{12}$ ).

$$
\begin{gathered}
\text { [Teu namorado] } \underset{\downarrow}{\leftrightarrow} \text { [é um chiclete }] \\
\downarrow \\
\text { Interação }
\end{gathered}
$$

(Ocorre interação entre o tópico e o veículo)

Resultado da interação: Novo elemento (operação mental - X) ${ }^{13}$

Quadro 05: Interação entre elementos que compõem a metáfora

\footnotetext{
${ }^{9}$ Por exemplo, há ausência da forma lexical “como”.

${ }^{10}$ Termo utilizado metaforicamente podendo significar: elaborar, gerar, criar.

${ }^{11}$ Em uma sentença metafórica, o tópico é o elemento ou a entidade sobre a qual se fala.

${ }^{12}$ Em uma metáfora, o veículo é a entidade que predica algo sobre o tópico.

${ }^{13}$ Elemento gerado, criado a partir da interação entre tópico e veículo, que constituem a metáfora.
} 
As autoras também propõem que às palavras ou às expressões que constituem uma metáfora são atribuídos sentidos que não lhes são próprios, mas de outras palavras ou expressões com as quais estabelecem alguma relação de semelhança. Diante dessa afirmação, questionamos, seriam esses sentidos emprestados de termos ${ }^{14}$ não envolvidos na constituição da metáfora, e então, atribuídos aos termos envolvidos na formação da sentença metafórica? Esses sentidos não seriam criados a partir da interação dos elementos lexicais que formam a metáfora? Novamente, observamos que a explicação apresentada no LDP não é clara o suficiente, gerando questionamentos. Finalizam a explicação argumentando que a metáfora está centrada na raiz do texto literário, sobre o que verificamos que as autoras ao fazerem essa afirmação se contradizem, pois ao introduzirem o assunto, na página 238, dão ênfase à ampliação do uso da metáfora, já na página 239, afirmam que a metáfora é prioridade do texto literário. Além disso, por que utilizaram, justamente, tirinhas para exemplificar que a metáfora é parte da raiz do texto literário? Por que não utilizaram um poema ou trecho de um texto literário? Por meio do exemplo apresentado neste LDP, é possível concluir que a metáfora não só é parte do texto literário, como também está presente em outros gêneros textuais, como as tirinhas.

E, por fim, analisamos o LDP, Vozes do Mundo, da editora Saraiva, de 2013. As autoras deste manual são Lília Santos Abreu-Tardelli, Lucas Sanches Oda, Maria Tereza Arruda Campos e Salete Toledo. Nesta obra, a metáfora faz parte do denominado grupo de figuras de palavras.

\section{Figuras de palavras}

As figuras de palavras consistem na utilização de palavras fora de seu sentido mais comum com a finalidade de criar novos recursos expressivos.

\section{Metáfora}

A metáfora é uma comparação mais aberta, sem marcação linguística, cujo elemento de semelhança fica implícito. Essa figura de linguagem também está presente na linguagem cotidiana. Veja os exemplos nesta notícia.

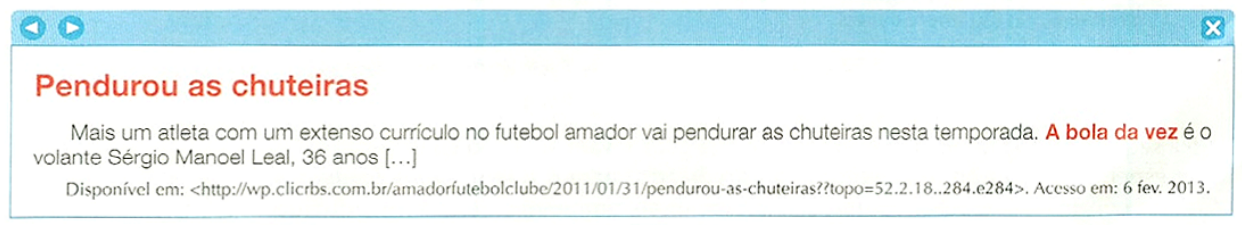

Para entendermos as metáforas acima, temos que identificar o elemento de comparação que está implícito. A expressão pendurou as chuteiras remete ao vocabulário do futebol, mas não é usada aqui no sentido literal; significa que o jogador se aposentou.

Já a expressão a bola da vez se refere à bola do jogo de sinuca que é escolhida a cada vez. Ser a bola da vez é ser o centro das atenções no momento.

Quadro 06: Explicação concernente à metáfora

Fonte: Abreu-Tardelli et al. (2013, p.308)

As autoras introduzem o assunto explicando que as figuras de palavras consistem na utilização de palavras fora do seu sentido mais comum. Neste caso, perguntamos o que seria utilizar uma palavra fora do sentido comum? O que seria o sentido comum das palavras, como explicá-lo? E o que seria o sentido não comum das palavras? É um conceito que gera discussão e muitos questionamos, ressaltamos que qualquer recurso linguístico faz uso de sentidos variados. Alertamos que, para Lakoff e Johnson (2002 [1980]), as metáforas são figuras do pensamento, e não de palavras, conforme utilizado no referido livro didático, visto que a origem da metáfora é na mente e não na língua, segundo a Teoria da Metáfora Conceptual. Além disso, as autoras afirmam que a figura de palavra tem a finalidade de criar novos recursos expressivos. Diante dessa asserção, novamente, questionamos, afinal que novos recursos expressivos seriam esses e como a figura de palavra cria esses recursos? São questões que carecem de explicação. Portanto, verificamos que, neste LDP, logo na introdução do assunto que diz respeito à metáfora há questões que necessitam de explicações mais acuradas.

\footnotetext{
${ }^{14}$ Palavras, expressões, formas lexicais.
} 
Os autores, ao conceituarem a metáfora como uma comparação mais aberta, sem marcação linguística, com elemento de semelhança implícito, tentam, conforme analisado nos LDPs anteriores, mostrar que expressões comparativas não estão presentes de forma explícita na estrutura da sentença metafórica. Na sequência, afirmam que essa figura de linguagem também está presente na linguagem cotidiana. Concluímos que uso do também na afirmação é uma forma de alertar o aluno e o professor, usuários do LDP, de que a metáfora é um recurso presente na linguagem diária. No conceito, não é justificado por que a metáfora está presente na linguagem do dia a dia. Diante desta questão, justificamos que a metáfora é um recurso que faz parte da cognição humana, por isso está onipresente na linguagem diária. Verificamos, novamente, que o conceito lançado não valoriza o fator cognitivo da metáfora.

Conforme ressaltamos na introdução desta seção, o propósito central deste estudo foi analisar como a metáfora é conceituada e explicada nos LDPs atuais. Também objetivamos alcançar uma resposta viável para o questionamento (iii) Qual é o conceito de metáfora que veicula nos LDPs atuais? Desta forma, pretendíamos verificar se a metáfora ainda é conceituada como um recurso ornamental da linguagem, ou se houve alguma evolução na maneira como ela é discutida nos compêndios escolares. Tal como já esclarecido, a escolha dos LDPs, para a realização deste estudo, não ocorreu de maneira casual, pois interessaram-nos os LDPs que foram avaliados recentemente no âmbito do PNLD. Ressaltamos que os resultados aqui apresentados não são conclusivos ou exaustivos, porém, com base na análise realizada, verificamos que os LDPs atuais reiteram o conceito tradicional da metáfora, como um recurso preponderantemente ornamental, que está ligado à linguagem figurada e ao campo da literatura.

\section{BREVE CONSIDERAÇÃO FINAL}

O objetivo principal deste estudo foi discutir e analisar como a metáfora vem sendo conceituada e explicada nos Livros Didáticos atuais de Língua Portuguesa. Conforme apresentado ao longo deste texto, a partir da pesquisa desenvolvida, verificamos que são, especialmente, os LDPs destinados às primeiras séries do Ensino Médio da Educação Básica que fazem alusão às figuras de linguagem. Dentre essas figuras apresentadas nesses materiais escolares, está a metáfora. Com base nesta pesquisa, verificamos que a metáfora ainda é compreendida e propagada nos LDPs atuais como uma simples figura retórica que desempenha a função de ornamentar/embelezar a linguagem. Tal conjuntura nos leva a presumir que, embora os LDPs sejam avaliados no âmbito do PNLD, alguns conteúdos ainda são transmitidos sob o enfoque tradicional e de maneira bastante breve e superficial. Como exemplo, temos os conceitos de metáfora, que são apresentados nos materiais escolares recentes, os quais não apreciam, ou consideram pouco e de maneira confusa, as teorias e os estudos que surgiram com o decorrer dos tempos sobre esse recurso da linguagem. Isso também contribui para que a metáfora ainda seja compreendida pela maioria dos alunos e dos professores como um simples recurso ornamental da linguagem, sendo estudada apenas nas aulas de literatura.

Bunzen (2014) informa que os pesquisadores e avaliadores de Livros Didáticos nos mostram as múltiplas faces que os materiais didáticos apresentam - como as características físicas, discursivas e suas finalidades sociais, ou seja, a forma como transmitem e discutem conhecimentos científicos - mas, diante deste estudo, apresentado neste artigo, chegamos à conclusão de que muitas vezes analisam superficialmente conteúdos tão importantes, dentre estes os estudos linguísticos-semânticos voltados para o ensino e a aplicabilidade da metáfora.

Dessa forma, concordamos com Batista (2014) quando esclarece que o livro deve ser um apoio ao ensino e ao aprendizado e não um material que condiciona, orienta e organiza a ação docente, ou apenas uma metodologia de ensino. Temos em mente que o lugar do Livro Didático, hoje, na prática docente não pode constituir-se como referência apenas no currículo da escola, selecionando os conteúdos, determinando sua progressão, definindo estratégias e/ou metodologias de trabalho, mas também como referência teórica fundamental e indispensável na tematização dos conhecimentos e (in)formação do professor sobre os aspectos da língua e da linguagem. Por fim, mesmo que os livros analisados neste artigo apresentem inconsistências no que diz respeito à metáfora, caracterizamo-los como fonte de informação significativa para o professor e como espaço educativo que possibilita a aprendizagem. 


\section{REFERÊNCIAS}

ABREU-TARDELLI, L. et al. Vozes do Mundo: Literatura, Língua e Produção de Texto. v. 1 (1ª série do Ensino Médio). Editora Saraiva: São Paulo, 2013.

AGÊNCIA BRASIL. 98\% dos professores de escolas públicas usam livros didáticos. Disponível em:_http://ultimosegundo.ig.com.br/educacao/2013-0227/98-dos-professores-de-escolas-publicas-usam-livros-didaticos.html>. Acesso em:30 mar. 2015.

ARISTÓTELES. Poética. Tradução: Eudoro de Souza. Porto Alegre: Editora Globo, 1996.

BATISTA, A. A. A avaliação dos livros didáticos: para entender o Programa Nacional do Livro Didático (PNLD). In: ROJO, Roxane; BATISTA, Antônio (Org.). Livro didático de Língua Portuguesa, Letramento e Cultura da Escrita. Campinas, SP: Mercado de Letras, 2003. p. 25-67.

BEZERrA, M. A. Ensino de língua portuguesa e contextos teórico-metodológicos. In: DIONÍSIO, A. P. MACHADO, A. R. BEZERRA, M. A. (Org.). Gêneros textuais e ensino. 5. Ed. Rio de Janeiro: Lucerna, 2007. p. 37-46.

BRASIL. Guia de Livros Didáticos: PNLD 2015. Apresentação: ensino médio. Brasília: Ministério da Educação, Secretaria da Educação Básica, 2014.

BUNZEN, C. Reapresentação de objetos de ensino em livros didáticos de Língua Portuguesa: um estudo exploratório. In: SIGNORINI, Inês. (Org.). Significados da Inovação no Ensino de Língua Portuguesa e na Formação de Professores. Campinas: Mercado de Letras, 2007. p. 79-110.

Livro didático de Língua Portuguesa: um gênero do discurso. 2005. 168 f. (Dissertação em Linguística Aplicada). Curso de Pós-Graduação em Linguística Aplicada, Universidade Estadual de Campinas, Campinas, SP, 2005.

BUNZEN, C. Análise de Livros Didáticos de Portuguesa no Campo da Linguística Aplicada: Possibilidades e Desafios. In: GONÇALVES, A. V.; SILVA, W. R.; GÓIS, M. L. de S. (Org.). Visibilizar a Linguística Aplicada: Abordagens Teóricas e Metodológicas. 1. ed. Campinas: Pontes, 2014, p. 269-292.

BLACK, M. Models and metaphor. Ithaca, NY: Cornell University Press, 1962.

Como as metáforas funcionam: uma resposta a D. Davidson. In: SACKS, Sheldon (Org.). Da metáfora. São Paulo: Educ, 1992, p. 183-193.

. More about metaphor. In: ORTONY, A. (Ed.). Metaphor and thought. Cambridge: Cambridge University Press, 1993. p. 19-41.

Modelos y metáforas. Madrid: Editorial Tecnos, 1966.

CAMPOS, E.; CARDOSO, P. M.; ANDRADE, S. L. Viva Português. 2. ed., v. 1 (1 a série do Ensino Médio). Editora Ática: São Paulo, 2013.

CHOPPIN, A. História dos livros e das edições didáticas sobre o estado da arte. In: Educação e Pesquisa. São Paulo, v. 30, n. 3, p. 549566, 2004. 
COHEN, J. Estrutura da linguagem poética. São Paulo: Cultrix, 1974.

COIMBRA, R. L. A linguagem metafórica. 1999. 603 f. Tese (Doutorado em Letras/Linguística) - Curso de Pós-Graduação em Letras/Linguística, Universidade de Aveiro, Aveiro, 1999.

FOSSILE, D. K. Um passeio pelos estudos da metáfora. Revista de Letras, Curitiba, n. 14, p. 01-15, 2011.

. O significado aspectual na interpretação de metáforas verbais. 2011.300 f. Tese (Doutorado em Linguística) - Curso de PósGraduação em Linguística, Universidade Federal de Santa Catarina, Florianópolis, 2011.

. Afinal, quando interpretamos uma sentença metafórica, realmente, conseguimos parafraseá-la? Revista de Letras, Curitiba, n.17,p. $01-15,2013 a$.

. Parece que as coisas estão mudando: aos poucos a semântica começa a aparecer nos livros didáticos de língua portuguesa. Linguagem e Ensino, Pelotas, v. 16, n. 2, p. 393-414, jul./dez. 2013 b.

Metáfora: alunos do ensino fundamental e professores em formação inicial encarando uma cilada que captura o(s) significado(s). In: SILVA, W. R. SANTOS, J. S. dos. MELO, M. A. de (Org.). Pesquisas em língua(gem) e demandas do Ensino Básico. Campinas - SP: Pontes Editores, 2014. p. 157-183.

HERNANDES, R.; MARTIN, V, L. Língua Portuguesa. v. 1 (1ª série do Ensino Médio). Editora Positivo: Curitiba, 2013.

LAKOFF, G.; JOHNSON, M. Metaphors we live by. Chicago: Chicago University Press, 1980.

. Metáforas da vida cotidiana. Tradução de M. S. Zanotto e V. Maluf. São Paulo: Educ, 2002.

MORAIS, M. E. G. Abordagem semântica nos manuais do Ensino Médio: um percurso além do Livro Didáticos de Português. 2013. 55 f. Trabalho de Conclusão de Curso (Graduação em Letras, com habilitação em Língua Portuguesa) - Universidade Federal da Paraíba, Campina Grande-PB, 2013.

MOURA, H. M. M.; PEREIRA, I. Máquinas e mentes: interpretando a metáfora. Working papers. Florianópolis, v. 9, n. 1, p. 81- 99, jan./jun. 2008.

RICOEUR, P. A metáfora viva. São Paulo: Edições Loyola, 2005.

SÁBATO, E. Sobre a metáfora. In: 117. O escritor e seus fantasmas. Tradução: Janer Cristaldo. Rio de Janeiro: F. Alves, 1982. p. 
SARDINHA, T. B. Metáfora. São Paulo: Parábola Editorial, 2007.

SILVA, W. Os exercícios da compreensão em Livros Didáticos do Ensino Médio. 144f. 1997. Dissertação (Mestrado em Letras) Curso de Pós-Graduação em Letras, Universidade Federal de Pernambuco, Recife, 1997.

ZANOTTO, M. S. Metáfora, Cognição e Ensino de Leitura. DELTA. Documentação de Estudos em Linguística Teórica e Aplicada, Sao Paulo, v. 11, n. 2, p. 241-254, 1995.

Metáfora e indeterminação: abrindo a caixa de Pandora. In: PAIVA, V. L. M. de O. e (Org.). Metáforas do cotidiano. Belo Horizonte: Ed. do Autor, 1998, p. 13-38.

ZANOTTO, M. S.; PALMA, D. V. Metáfora, cognição e ensino de leitura: o pensar metafórico em sala de aula. In: BASTOS, Neusa Barbosa (Org.). Língua Portuguesa: Histórias, Perspectivas, Ensino. São Paulo/SP: EDUC, 1998. 